\title{
The association between ownership of common household devices and obesity and diabetes in high, middle and low income countries
}

\author{
Scott A. Lear PhD, Koon Teo MB PhD, Danijela Gasevic MD, Xiaohe Zhang MSc, Paul P. Poirier MD PhD, \\ Sumathy Rangarajan MSc, Pamela Seron MSc, Roya Kelishadi MD, Azmi Mohd Tamil MPH, \\ Annamarie Kruger PhD, Romaina Iqbal PhD, Hani Swidan MD, Diego Gómez-Arbeláez MD, Rita Yusuf PhD, \\ Jephat Chifamba MPhil, V. Raman Kutty MD, Kubilay Karsıdag MD, Rajesh Kumar MD, Wei Li PhD, \\ Andrzej Szuba MD PhD, Alvaro Avezum MD, Rafael Diaz MD, Sonia S. Anand MD, Annika Rosengren MD, \\ Salim Yusuf MD DPhil; on behalf of the Prospective Urban Rural Epidemiology (PURE) study
}

See related editorial by Patrick on page 243 and at www.cmaj.ca/lookup/doi/10.1503/cmaj.140113

Competing interests: None declared.

This article has been peer reviewed.

Correspondence to:

Scott Lear,

slear@providencehealth.bc.ca

CMAJ 2014. DOI:10.1503 /cmaj.131090

\section{ABSTRACT}

Background: Household devices (e.g., television, car, computer) are common in high income countries, and their use has been linked to obesity and type 2 diabetes mellitus. We hypothesized that device ownership is associated with obesity and diabetes and that these effects are explained through reduced physical activity, increased sitting time and increased energy intake.

Methods: We performed a cross-sectional analysis using data from the Prospective Urban Rural Epidemiology study involving 153996 adults from high, upper-middle, lower-middle and low income countries. We used multilevel regression models to account for clustering at the community and country levels.

Results: Ownership of a household device increased from low to high income countries ( $4 \%$ to $83 \%$ for all 3 devices) and was associated with decreased physical activity and increased sitting, dietary energy intake, body mass index and waist circumference. There was an increased odds of obesity and diabetes with the ownership of any 1 household device compared to no device ownership (obesity: odds ratio [OR] 1.43, 95\% confidence interval [Cl] 1.32-1.55; diabetes: OR 1.38, 95\% Cl 1.28-1.50). Ownership of a second device increased the odds further but ownership of a third device did not. Subsequent adjustment for lifestyle factors modestly attenuated these associations. Of the 3 devices, ownership of a television had the strongest association with obesity (OR 1.39, 95\% Cl 1.291.49) and diabetes (OR 1.33, 95\% Cl 1.23-1.44). When stratified by country income level, the odds of obesity and diabetes when owning all 3 devices was greatest in low income countries (obesity: OR 3.15, 95\% Cl 2.33-4.25; diabetes: OR $1.97,95 \% \mathrm{Cl} 1.53-2.53$ ) and decreased through country income levels such that we did not detect an association in high income countries.

Interpretation: The ownership of household devices increased the likelihood of obesity and diabetes, and this was mediated in part by effects on physical activity, sitting time and dietary energy intake. With increasing ownership of household devices in developing countries, societal interventions are needed to mitigate their effects on poor health.
$\mathrm{T}$ he increasing global prevalence of obesity and type 2 diabetes mellitus has been driven predominantly by increases in high income countries. ${ }^{1,2}$ However, increases are expected in low and middle income countries, due in part to rapid development and industrialization.

Proximal determinants of obesity and diabetes include energy expenditure and intake, $;^{3-5}$ however, the upstream factors are complex and entail numerous environmental factors. Of these, the increased use of common household devices (e.g., televisions, cars, computers) has been linked to increased sitting, decreased physical activity, obesity, metabolic syndrome and diabetes. ${ }^{6-12}$ Time spent watching television has also been linked to poor diet ${ }^{13}$ and increased caloric intake. ${ }^{14}$ However, these findings are based on studies in high income countries where the ownership of these devices is common. ${ }^{15,16}$ In low and middle income countries, such household devices are less prevalent, but their prevalence is rapidly 
increasing. Studies in countries with greater variability in the ownership of household devices are needed to understand the full effect of owning such devices on the risk of obesity and diabetes.

We hypothesized that the ownership of a television, car or computer would be associated with an increased risk of obesity and diabetes and that these effects would be explained by reduced physical activity, increased sitting time and increased energy intake.

\section{Methods}

\section{Study design}

Participants in the Prospective Urban Rural Epidemiologic (PURE) study were enrolled from 17 high income countries (Canada, Sweden, United Arab Emirates), upper-middle income countries (Argentina, Brazil, Chile, Malaysia, Poland, South Africa, Turkey), lower-middle income countries (China, Colombia, Iran) and low income countries (Bangladesh, India, Pakistan, Zimbabwe) (Appendix 1, available at www.cmaj.ca/lookup/suppl /doi:10.1503/cmaj.131090/-/DC1). Detailed methods have been published. ${ }^{17}$

The choice of countries reflects our desire to involve a large number of communities at different economic levels with heterogeneity in social and economic environments as well as the feasibility of successful long-term follow-up. Cities and towns were identified to reflect the geographical diversity of the selected countries, and urban and rural areas were identified in and around these cities and towns. In geographically larger and more populous countries (e.g., India, China), multiple cities and towns were selected. Communities from low, middle and high income areas were selected from within the cities and towns. Communities were identified based on the clustering of common characteristics (shared culture, socioeconomic status) and geographically defined as a set of contiguous postal code areas or group of streets or a small village. For reasons of practicality, we did not aim for a strict proportionate sampling of the world or of any specific country or region; however we did aim to recruit from economically, culturally and geographically diverse areas worldwide.

Within each community, all households were approached, and individuals aged 35-70 years who intended to remain at their current address for 4 years were invited to participate. The method of approaching households was different depending on the country but was consistent across sites within each country. These methods generally consisted of 2 approaches: initial announcements in the target communities, followed by door-to-door visits by study personnel; or study invitations mailed to all households within the target communities, followed by telephone calls from study personnel. At least 3 attempts were made to contact an individual in each household. The household participation rate was $86 \%$.

This study was approved by the Hamilton Integrated Research Ethics Board and all relevant institutional research ethics boards at all recruitment sites.

\section{Assessment}

Participants underwent an assessment either at home, at a mobile clinic held in their community or at a central research centre. Measures were standardized and conducted identically to the procedures in the INTERHEART study.$^{18}$ Standard equipment was provided to each site, and key staff from each site attended an initial training session; they in turn trained local staff on these methods. Household ownership of a television, car or computer was self-reported. As an indicator of personal household income, we calculated percentage of income spent on food as follows: reported monthly food expenditures divided by monthly household income. Physical activity and sitting time were assessed using the long-form International Physical Activity Questionnaire and are reported in metabolic equivalents $(\mathrm{min} / \mathrm{wk}) .{ }^{19}$

Where available, existing validated food frequency questionnaires were used. In countries where food frequency questionnaires were not available, country-specific food frequency questionnaires were developed and validated. ${ }^{20-25} \mathrm{To}$ enable comparability of all nutrition-related data and calculation of nutrient content, a master international nutrient database was created and modified appropriately to include local food composition tables and recipes of local dishes.

Body mass index (BMI) was calculated from measured height and weight, using a stadiometer and electronic scale, respectively. We defined obesity as a BMI of 30 or greater. Waist circumference was determined as the average of 2 measurements taken midway between the lowest rib and the top of the iliac crest directly on the skin or close-fitting clothing at the end of normal expiration using a nonflexible tape measure attached to a spring balance exerting a force of $750 \mathrm{~g}$. Type 2 diabetes was defined as either self-reported diabetes or fasting glucose level of $7 \mathrm{mmol} / \mathrm{L}$ or greater.

\section{Statistical analyses}

We report continuous variables means and standard deviations and categorical variables as proportions. All models considered 3 levels of clus- 
tering because the individual participants were nested in communities and the communities were nested in countries. The variance of the outcome is partitioned across levels of the nested data, between-country variation, within-country and between-community variation and withincommunity and between-individual variation. The basic multilevel model used is shown below, where $i$ represents level 1 (individual), $j$ represents level 2 (community) and $k$ represents level 3 (country). Level 1 variables are represented by the subscripts $i j k$, level 2 variables are represented by the subscripts $j k$ and level 3 variables are represented by the subscript $k$. The regression coefficients are shown by beta coefficients $(\beta)$; these are the fixed effects to be interpreted the same way as the coefficients from an ordinary least squares regression:

$y_{i j k}=\beta_{0}+\beta_{1} X_{1 j k}+\beta_{2} X_{2 i j k}+\ldots+\beta_{\mathrm{m}} X_{m i j k}+\left(v_{k}+\mu_{j k}+\varepsilon_{i j k}\right)$

The random effect $v_{\mathrm{k}}$ represents the variation in intercepts between countries and the random effect $\mu_{j k}$ represents the variation in intercepts between communities within countries. The variable $\varepsilon_{i j k}$ stands for the variation between individuals within communities. The fixed intercept $\beta_{0}$ is the overall average for the outcome.

To eliminate the effects from potential con- founders, we adjusted the means or proportions for other covariates by using the GLIMMIX procedure in SAS. Country- and community-level clustering were included as random effects. The associations of obesity and diabetes with ownership of household devices were assessed with logistic regression models after adjustment for other covariates and taking country- and community-level clustering into consideration. To address the study hypothesis, a sequence of multilevel regression models was used to assess the relation between household device ownership and obesity and diabetes while first taking into account economic factors followed by the inclusion of the potential mediating lifestyle factors (physical activity, sitting time and caloric intake). Odds ratios (ORs) and 95\% confidence intervals (CIs) were derived using GLIMMIX procedure. All analyses were performed in SAS version 9.2.

\section{Results}

A total of 153996 participants from 107599 households were included in the analyses. There was a gradient in decreased percentage of income spent on food and higher education with increasing ownership of household devices (Table 1). Ownership of a television was most common

Table 1: Participant demographics, stratified by the number of devices* owned

\begin{tabular}{|c|c|c|c|c|}
\hline \multirow[b]{2}{*}{ Characteristic } & \multicolumn{4}{|c|}{ No. of participants (\%)† } \\
\hline & $\begin{array}{l}\text { No devices } \\
n=17798\end{array}$ & $\begin{array}{c}1 \text { device } \\
n=71090\end{array}$ & $\begin{array}{c}2 \text { devices } \\
n=29938\end{array}$ & $\begin{array}{c}3 \text { devices } \\
n=30136\end{array}$ \\
\hline Age, yr, mean \pm SD & $49.4 \pm 10.3$ & $50.4 \pm 10.2$ & $50.8 \pm 9.8$ & $50.9 \pm 9.3$ \\
\hline Male & $7517(42.2)$ & $28601(40.2)$ & $12738(42.5)$ & $13790(45.8)$ \\
\hline \multicolumn{5}{|l|}{ Education } \\
\hline $\begin{array}{l}\text { None, primary or } \\
\text { unknown }\end{array}$ & $11846(67.0)$ & $35868(50.6)$ & $10822(36.2)$ & $5076(16.9)$ \\
\hline $\begin{array}{l}\text { Secondary, high, } \\
\text { higher secondary } \\
\text { school }\end{array}$ & $4905(27.8)$ & $28827(40.7)$ & $12371(41.4)$ & $10320(34.3)$ \\
\hline $\begin{array}{l}\text { Trade, college or } \\
\text { university }\end{array}$ & $924(5.2)$ & $6198 \quad(8.7)$ & $6700(22.4)$ & 14723 (48.9) \\
\hline \multicolumn{5}{|l|}{ Country income level } \\
\hline High & $50 \quad(0.3)$ & 379 (0.5) & 1959 (6.5) & $13615(45.2)$ \\
\hline Upper-middle & $2337(13.1)$ & $15230(21.4)$ & $13444(44.9)$ & $11113(36.9)$ \\
\hline Lower-middle & 6206 (34.9) & 37007 (52.1) & $11990(40.0)$ & $3984(13.2)$ \\
\hline Low & $9205(51.7)$ & $18474(26.0)$ & $2545 \quad(8.5)$ & 1424 (4.7) \\
\hline $\begin{array}{l}\text { Percentage of } \\
\text { income spent on } \\
\text { food, mean } \pm S D\end{array}$ & $61.6 \pm 25.9$ & $48.7 \pm 23.5$ & $40.5 \pm 21.2$ & $26.3 \pm 20.3$ \\
\hline
\end{tabular}


(78\%); $32.0 \%$ of households owned a car and $34.2 \%$ owned a computer (Table 2). Ownership of any of the 3 devices was greatest in the high income countries and decreased with decreasing country income. For all 3 devices, ownership of a household device increased from $4 \%$ to $83 \%$ in low to high income countries, respectively. Ownership of household devices was higher in urban areas than in rural areas and in upper-middle, lower-middle and low income countries. The difference between urban and rural areas increased with decreasing country income.

Increased household devices ownership was associated with increased sitting, dietary energy intake, BMI and waist circumference and decreased physical activity (Table 3 ). These trends were more prominent in the low income countries than in the high income countries. For example, in low income countries, ownership of all 3 household devices was associated with a $31 \%$ decrease in physical activity, a $21 \%$ increase in sitting and a 9-cm increase in waist circumference, compared with owning none of the devices $(p<0.001$ for trend for all).

Ownership of a television was associated with an increased odds of obesity (adjusted OR 1.39,
95\% CI 1.29-1.49) and diabetes (adjusted OR $1.33,95 \%$ CI 1.23-1.44), after taking into account community- and country-level clustering and adjustment for covariates (Table 4). Further adjustment for economic factors, physical activity, sitting time and energy intake attenuated but did not remove this association (obesity: adjusted OR 1.33, 95\% CI 1.21-1.45; diabetes: adjusted OR 1.22 , 95\% CI 1.12-1.34).

Ownership of a car was associated with an increased odds of obesity (OR 1.14, 95\% CI 1.08-1.19) but not diabetes. This association persisted after adjustment for physical activity, sitting time and energy intake (adjusted OR 1.14, 95\% CI 1.08-1.20). There was no association between ownership of a computer only and obesity or diabetes. In upper-middle income countries, ownership of a television or car was associated with obesity. In low income countries, ownership of a television, car or computer was associated with obesity and diabetes (Appendix 2, available at www.cmaj.ca/lookup/suppl/doi:10 .1503/cmaj.131090/-/DC1).

There was increased odds of obesity and diabetes with the ownership of any 1 household device, after taking community- and country-level

Table 2: Household device ownership, stratified by country income level and urban or rural residence location*

\begin{tabular}{|c|c|c|c|c|c|c|c|c|c|}
\hline \multirow[b]{3}{*}{$\begin{array}{l}\text { Device† } \\
\text { ownership }\end{array}$} & \multirow{3}{*}{$\begin{array}{c}\text { No. of } \\
\text { households } \\
n=107599\end{array}$} & \multicolumn{8}{|c|}{ No. (\%) of participants } \\
\hline & & \multicolumn{2}{|c|}{ High income } & \multicolumn{2}{|c|}{ Upper-middle income } & \multicolumn{2}{|c|}{ Lower-middle income } & \multicolumn{2}{|c|}{ Low income } \\
\hline & & $\begin{array}{c}\text { Urban } \\
n=8970\end{array}$ & $\begin{array}{c}\text { Rural } \\
n=3343\end{array}$ & $\begin{array}{c}\text { Urban } \\
n=17417\end{array}$ & $\begin{array}{c}\text { Rural } \\
n=14016\end{array}$ & $\begin{array}{c}\text { Urban } \\
n=20900\end{array}$ & $\begin{array}{c}\text { Rural } \\
n=19867\end{array}$ & $\begin{array}{c}\text { Urban } \\
n=10730\end{array}$ & $\begin{array}{c}\text { Rural } \\
n=12356\end{array}$ \\
\hline Television & $\begin{array}{c}89785 \\
(83.4)\end{array}$ & $\begin{array}{l}8725 \\
(97.3)\end{array}$ & $\begin{array}{l}3269 \\
(97.8)\end{array}$ & $\begin{array}{l}16220 \\
(93.1)\end{array}$ & $\begin{array}{l}11795 \\
(84.2) \S\end{array}$ & $\begin{array}{l}18554 \\
(88.8)\end{array}$ & $\begin{array}{l}16864 \\
(84.9) \S\end{array}$ & $\begin{array}{l}8918 \\
(83.1)\end{array}$ & $\begin{array}{l}5440 \\
(44.0) \S\end{array}$ \\
\hline Car & $\begin{array}{c}32430 \\
(30.1)\end{array}$ & $\begin{array}{l}8034 \\
(89.6)\end{array}$ & $\begin{array}{l}3212 \\
(96.1) \S\end{array}$ & $\begin{array}{l}8901 \\
(51.1)\end{array}$ & $\begin{array}{c}6083 \\
(43.4) \S\end{array}$ & $\begin{array}{l}3104 \\
(14.9)\end{array}$ & $\begin{array}{l}1484 \\
(7.5) \S\end{array}$ & $\begin{array}{l}1332 \\
(12.4)\end{array}$ & $\begin{array}{c}280 \\
(2.3) \S\end{array}$ \\
\hline Computer & $\begin{array}{c}32627 \\
(30.3)\end{array}$ & $\begin{array}{l}8101 \\
(90.3)\end{array}$ & $\begin{array}{l}2916 \\
(89.2) \S\end{array}$ & $\begin{array}{l}7575 \\
(43.5)\end{array}$ & $\begin{array}{l}2870 \\
(20.5) \S\end{array}$ & $\begin{array}{l}8390 \\
(40.1)\end{array}$ & $\begin{array}{l}1273 \\
(6.4) \S\end{array}$ & $\begin{array}{l}1369 \\
(12.8)\end{array}$ & $\begin{array}{c}133 \\
(1.1) \S\end{array}$ \\
\hline \multicolumn{10}{|l|}{ No. of devices } \\
\hline 2 & $\begin{array}{c}20422 \\
(19.0)\end{array}$ & $\begin{array}{r}1182 \\
(13.2)\end{array}$ & $\begin{array}{c}458 \\
(13.7)\end{array}$ & $\begin{array}{l}5016 \\
(28.8)\end{array}$ & $\begin{array}{l}4126 \\
(29.4)\end{array}$ & $\begin{array}{l}6469 \\
(31.0)\end{array}$ & $\begin{array}{l}1682 \\
(8.5) \S\end{array}$ & $\begin{array}{l}1203 \\
(11.2)\end{array}$ & $\begin{array}{c}286 \\
(2.3) \S\end{array}$ \\
\hline 3 & $\begin{array}{c}21582 \\
(20.1)\end{array}$ & $\begin{array}{l}7398 \\
(82.5)\end{array}$ & $\begin{array}{c}2809 \\
(84.0) \ddagger\end{array}$ & $\begin{array}{l}5624 \\
(32.3)\end{array}$ & $\begin{array}{c}2298 \\
(16.4) \S\end{array}$ & $\begin{array}{l}2219 \\
(10.6)\end{array}$ & $\begin{array}{c}475 \\
(2.4) \S\end{array}$ & $\begin{array}{l}711 \\
(6.6)\end{array}$ & $\begin{array}{c}48 \\
(0.4) \S\end{array}$ \\
\hline $\begin{array}{l}\text { Percentage of } \\
\text { income spent } \\
\text { on food, } \\
\text { mean } \pm \text { SD }\end{array}$ & $\begin{array}{c}44.1 \\
\pm 25.3\end{array}$ & $\begin{array}{c}13.8 \\
\pm 12.0\end{array}$ & $\begin{array}{c}15.9 \\
\pm 14.3 \S\end{array}$ & $\begin{array}{c}36.1 \\
\pm 19.8\end{array}$ & $\begin{array}{c}47.7 \\
\pm 23.2 \S\end{array}$ & $\begin{array}{c}47.1 \\
\pm 21.4\end{array}$ & $\begin{array}{c}44.8 \\
\pm 23.8 \S\end{array}$ & $\begin{array}{c}49.7 \\
\pm 23.9\end{array}$ & $\begin{array}{c}68.1 \\
\pm 22.7 \S\end{array}$ \\
\hline $\begin{array}{l}\text { Note: } \mathrm{SD}=\text { standar } \\
* \text { Urban and rural } \\
+\mathrm{Car} \text {, television, co } \\
\neq p<0.05 \text {, urban } v \text {. } \\
\S p<0.001 \text {, urban }\end{array}$ & $\begin{array}{l}\text { d deviation. } \\
\text { values indicate t } \\
\text { mputer. } \\
\text { rural location. } \\
\text { rural location. }\end{array}$ & number 0 & sseholds. & & & & & & \\
\hline
\end{tabular}


clustering into account and adjustment for covariates (Table 5). This increase was greatest going from no device ownership to ownership of 1 device (obesity: OR 1.43, 95\% CI 1.32-1.55; dia- betes: OR 1.38, 95\% CI 1.28-1.50) and increased with owning a second device (obesity: OR 1.58, 95\% CI 1.45-1.73; diabetes: OR 1.43, 95\% CI 1.30-1.56). Ownership of a third device was asso-

Table 3: Anthropometry characteristics and physical activity level for high, upper-middle, lower-middle and low income countries, stratified by cumulative device ownership

\begin{tabular}{|lcccc} 
& \multicolumn{3}{c}{ Mean $(95 \%$ confidence interval) $\dagger$} \\
\cline { 2 - 5 } Variable; country income level & No devices & 1 device & 2 devices & 3 devices \\
\hline & $n=17798$ & $n=71090$ & $n=29938$ & $n=30136$ \\
\hline
\end{tabular}

Physical activity, metabolic

equivalents, * $\mathrm{min} / \mathrm{wk}$

High

Upper-middle

Lower-middle

Low

All

\section{Time spent sitting, $\mathrm{min} / \mathrm{wk}$}

High

Upper-middle

Lower-middle

Low

All

\section{Daily energy intake, kcal}

High

Upper-middle

Lower-middle

Low

All

Body mass index

High

$28.2(26.1-30.2)$ *

27.5 (26.5-28.6)

Upper-middle

Lower-middle

Low

25.8 (24.3-27.3)

22.1 (20.7-23.5)

$25.9(25.1-26.7)$

$1523(754.1-2292)$ *

1908 (1183-2633)

1511 (1039-1983)

1656 (948.4-2364)

1736 (1105-2367)

1703 (1382-2024)

$2422(1785-3059)$ *

2320 (1778-2862)

2138 (1787-2488)

2151 (1629-2672)

2446 (1979-2912)

2264 (2025-2502)

28.1 (26.4-29.7)

$28.8(27.8-29.8)$

$26.0(24.5-27.5)$

23.7 (22.3-25.0)

26.6 (25.9-27.3)

$92.1(86.8-97.4)$ *

91.6 (87.3-95.9)

92.5 (88.4-96.7)

90.9 (86.8-95.0)

High

Upper-middle

Lower-middle

89.7 (87.0-92.5)

84.8 (80.9-88.7)

91.9 (89.2-94.6)

$85.1(81.2-89.0)$

73.3 (69.6-76.9)

$85.0(83.0-87.0)$
77.7 (74.1-81.4)

$86.6(84.7-88.4)$
1957 (1236-2678)

2001 (1281-2721)§

1539 (1068-2011)

1553 (1081-2025)

1727 (1019-2436)

1713 (1005-2422)ๆ

1798 (1166-2430)

2029 (1397-2662)

1755 (1435-2076)

1824 (1504-2145)ף

2355 (1819-2891)

2434 (1899-2969)

2243 (1892-2593)

2274 (1923-2624)

2237 (1716-2759)

2356 (1834-2878)

2469 (2001-2937)

2480 (2010-2950)§

2326 (2089-2563)

2386 (2149-2624)‡

Low

All

*Sparse data; represents less than $1 \%$ of participants in high income countries.

tCountry and community level clusters were included in the model as random effects.

$\ddagger p$ for trend $<0.01$.

$\S p$ for trend $<0.001$

१ $p$ for trend $<0.001$ 
ciated with a decrease in likelihood. Subsequent adjustment for lifestyle factors had little effect on the association between household devices ownership and obesity; however, it modestly attenuated the association between device ownership and diabetes (OR 1.30, 95\% CI 1.19-1.42).

Figure 1 shows the prevalence of obesity and diabetes by cumulative number of household devices owned, stratified by country income level and adjusted for covariates. Although we found no trend between household devices ownership and obesity or diabetes in high income countries, there was a stronger relation as the level of country income decreased. This relation was most prominent in low income countries, such that the prevalence of obesity increased from $3.4 \%$ for no devices owned to $14.5 \%$ for 3 devices ( $p<0.001$ for trend). The prevalence of diabetes also increased (no devices: $4.7 \% ; 3$ devices: $11.7 \%)(p<0.001$ for trend).

There was a modest association between obesity and owning 3 devices in upper-middle (OR $1.35,95 \%$ CI $1.14-1.60)$ and lower-middle income countries (OR 1.37, 95\% CI 1.12-1.67) (Appendix 3, available at www.cmaj.ca/lookup /suppl/doi:10.1503/cmaj.131090/-/DC1). There was no association in upper-middle income countries after adjustment for lifestyle factors. In low income countries, there was a marked and stepped increase in the odds of obesity with increasing device ownership (3 devices: OR 3.15 , 95\% CI 2.33-4.25). There were no associations between household devices ownership and odds of diabetes in high (OR 1.69, 95\% CI 0.1125.6), upper-middle (OR 1.22 , $95 \%$ CI $0.96-$ 1.55 ) and lower-middle (OR $0.99,95 \%$ CI 0.79 1.25 ) income countries. In low income countries, owning 3 devices was associated with an increased odds of diabetes (OR 1.97, 95\% CI 1.53-2.53); however, adjustment for lifestyle factors attenuated this association (OR 1.67, 95\% CI 1.25-2.23).

\section{Interpretation}

Owning common household devices was associated with an increased risk of obesity and type 2 diabetes; however, this association varied by country income level. These associations were mediated, in part, through increased time spent sitting and energy intake and decreased physical activity.

The recent acknowledgement of the role of environment in the increasing prevalence of obesity and diabetes ${ }^{3-5}$ has been purported to be, in part, because of increased automation and decreased obligatory activity. Time spent watching television or using cars or computers has been associated with decreased physical activity, increased time spent sitting and subsequent obesity and diabetes..$^{6-12,15}$ We found that owning 1 household device was associated with an increased odds of obesity and diabetes; the greatest risk was associated with owning a television followed by a car.

In a previous study, ${ }^{26}$ we found that owning both a television and car was independently associated with an increased risk of nonfatal myocardial infarction. Our present findings suggest a possible causal pathway: increased eco-

Table 4: Odds of obesity and diabetes associated with household device ownership

\begin{tabular}{|c|c|c|}
\hline \multirow[b]{2}{*}{ Device; model†‡ } & \multicolumn{2}{|c|}{ Odds ratio ( $95 \%$ confidence interval)* } \\
\hline & $\begin{array}{c}\text { Obesity } \\
\text { (body mass index } \geq 30 \text { ) }\end{array}$ & Diabetes \\
\hline \multicolumn{3}{|l|}{ Television } \\
\hline Model 1 & 1.39 (1.29-1.49) & $1.33(1.23-1.44)$ \\
\hline Model 2 & $1.33(1.21-1.45)$ & $1.22(1.12-1.34)$ \\
\hline \multicolumn{3}{|l|}{ Car } \\
\hline Model 1 & $1.14(1.08-1.19)$ & $1.05(0.98-1.11)$ \\
\hline Model 2 & $1.14(1.08-1.20)$ & $1.02(0.95-1.09)$ \\
\hline \multicolumn{3}{|l|}{ Computer } \\
\hline Model 1 & $0.98(0.93-1.03)$ & $0.99(0.93-1.04)$ \\
\hline Model 2 & $0.99(0.94-1.04)$ & $0.96(0.90-1.02)$ \\
\hline \multicolumn{3}{|c|}{$\begin{array}{l}\text { *Ownership compared to nonownership. } \\
\text { † Model } 1 \text { adjusted for age, sex, percentage of income spent on food, education, urban or } \\
\text { rural location and country income. Model } 2=\text { Model } 1 \text { plus adjustment for total physical } \\
\text { activity, minutes spent sitting per week and average daily energy intake. } \\
\text { ‡Country- and community-level clustering were accounted for by use of a random effects } \\
\text { model. }\end{array}$} \\
\hline
\end{tabular}

Table 5: Odds of obesity and diabetes associated with cumulative household device* ownership

\begin{tabular}{|c|c|c|}
\hline \multirow[b]{2}{*}{ Model¥§ } & \multicolumn{2}{|c|}{ Odds ratio (95\% confidence interval) $\dagger$} \\
\hline & $\begin{array}{c}\text { Obesity } \\
\text { (body mass index } \geq 30 \text { ) }\end{array}$ & Diabetes \\
\hline \multicolumn{3}{|l|}{ Model 1} \\
\hline 1 device & $1.43(1.32-1.55)$ & $1.38(1.28-1.50)$ \\
\hline 2 devices & $1.58(1.45-1.73)$ & $1.43(1.30-1.56)$ \\
\hline 3 devices & $1.50(1.36-1.65)$ & $1.33(1.20-1.47)$ \\
\hline \multicolumn{3}{|l|}{ Model 2} \\
\hline 1 device & $1.39(1.26-1.54)$ & $1.30(1.19-1.42)$ \\
\hline 2 devices & $1.54(1.38-1.71)$ & $1.32(1.19-1.46)$ \\
\hline 3 devices & $1.46(1.30-1.64)$ & $1.16(1.03-1.31)$ \\
\hline \multicolumn{3}{|c|}{$\begin{array}{l}\text { *Television, car or computer. } \\
\text { tOwnership compared to nonownership. } \\
\text { fModel } 1 \text { adjusted for age, sex, percentage of income spent on food, education, urban or } \\
\text { rural location and country income; Model } 2 \text { = Model } 1 \text { plus adjustment for total physical } \\
\text { activity, minutes spent sitting per week and average daily energy intake. } \\
\text { §Country- and community-level clustering were accounted for by use of a random effects } \\
\text { model. }\end{array}$} \\
\hline
\end{tabular}


nomic development leads to increased household devices ownership, which may result in an increased risk of obesity and diabetes and potential downstream cardiovascular events.

Because country income level is a proxy for economic, social and environmental development, the 4 income levels that we chose reflect different stages in the epidemiologic transition. We found marked differences in associations based on country income level. Although we found a significant positive association between owning household devices and obesity or diabetes in low income countries, we were unable to detect a relationship at the high income country level. The associations in the upper-middle and lower-middle income countries were intermediate between the high and low risk countries. The inability to detect an association in high income countries likely reflects the homogeneity of device ownership (over $80 \%$ of participants in the high income countries reported owning all 3 devices; only $3 \%$ owned all 3 in the low income countries). Our findings may also be the result of a plateau effect of exposure to household devices (i.e., the negative effect of owning such devices has already occurred and is represented in the high prevalence of obesity and diabetes in these countries). Conversely, exposure to household devices in the low income countries has only recently begun and, therefore, the negative effects of their ownership are more acute and may increase as ownership increases.
Recent studies have indicated that excessive sitting is associated with obesity and diabetes, independent of physical activity. ${ }^{71,27}$ This may be because of downregulation of lipoprotein lipase and increased glucose levels. ${ }^{10,28}$ Sitting, and more specifically television watching, is associated with poor diet. ${ }^{13}$ Indeed, we found that the risk of obesity and diabetes associated with owning household devices was mediated through decreased physical activity and increased sitting time and dietary intake. Reduced sitting time has been associated with lower BMI in adolescents ${ }^{29}$ and may be a potential intervention opportunity. Sitting interspersed with short breaks of lowintensity activity (such as walking) may prevent the deleterious effects of prolonged sitting by improving glucose control. ${ }^{30,31}$ For many populations, economic development leads to a workplace in which sitting time is predominantly accumulated. Improving the ability to take short physical activity breaks and increasing activity during these periods, ${ }^{32,33}$ as well as redesigning work spaces to include standing desks, attractive staircases or small-group meetings conducted while walking, can also lead to increased physical activity while reducing sitting time.

\section{Limitations}

Because this study was cross-sectional, we cannot identify the causal pathways between household devices ownership and obesity or diabetes. Although owning these devices likely preceded

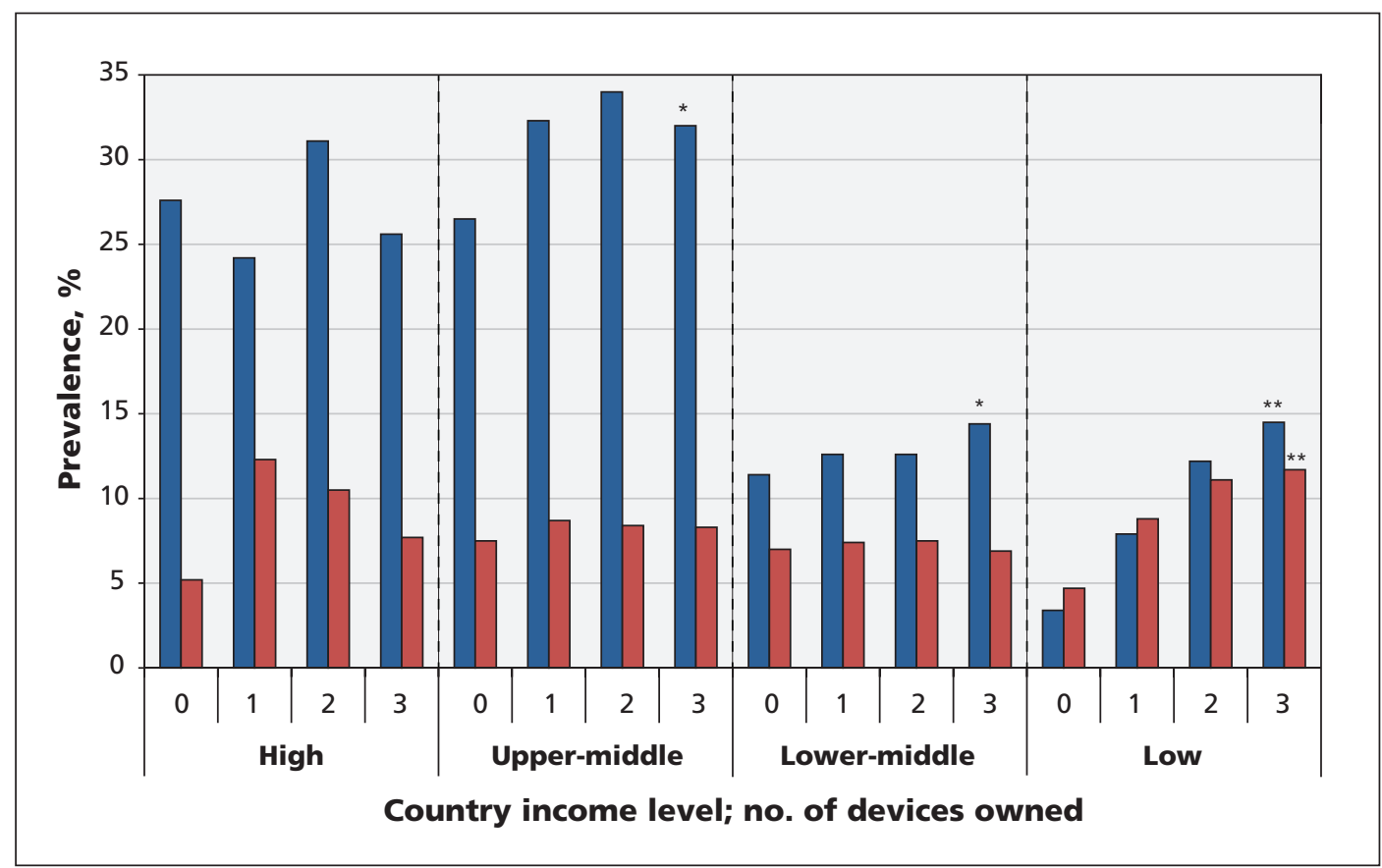

Figure 1: Prevalence of obesity (blue bars) and diabetes (red bars) by cumulative device ownership (television, car, computer) stratified by country income level and adjusted for age, sex, percentage of income spent on food, urban or rural location, education and country income. Country- and community-level clustering were accounted for in the analysis by use of a random effects model. ${ }^{*} p<0.01$ for trend, ${ }^{* *} p<0.001$ for trend. 
the increase in sedentary behaviours, it is possible that people who are obese or who have diabetes are more likely to own household devices because of a desire to be more sedentary and possible discomfort with physical activity. In addition, our measures of physical activity and sitting time were based on 1-week recall, which may not fully reflect the duration of exposure for a given device (e.g., a participant may have owned a television for several decades). Additionally, sedentary behaviours such as standing and low-intensity physical activity that may be important with respect to the relation between household devices and obesity or diabetes were not captured.

\section{Conclusion}

Ownership of common household devices such as a television, car or computer increased as country income level increased. Owning such devices was associated with increased odds of obesity and diabetes in low, lower-middle and upper-middle income countries. These associations were mediated, in part, through increased time spent sitting and daily energy intake and decreased physical activity. With rapid economic development in many low and middle income countries, the ownership of common household devices is likely to increase and result in increases in obesity and diabetes. Our findings emphasize the importance of limiting the amount of time spent using household devices, reducing sedentary behaviour and encouraging physical activity in the prevention of obesity and diabetes.

\section{References}

1. King H, Aubert RE, Herman WH. Global burden of diabetes, 1995-2025: prevalence, numerical estimates, and projections. Diabetes Care 1998;21:1414-31.

2. Organization WH. Obesity and overweight: Global strategy on diet, physical activity and health. Geneva (Switzerland): World Health Organization; 2003.

3. Kumanyika SK, Obarzanek E, Stettler N, et al. Population-based prevention of obesity: the need for comprehensive promotion of healthful eating, physical activity, and energy balance: a scientific statement from American Heart Association Council on Epidemiology and Prevention, Interdisciplinary Committee for Prevention (formerly the expert panel on population and prevention science). Circulation 2008;118:428-64.

4. Swinburn BA, Sacks G, Hall KD, et al. The global obesity pandemic: shaped by global drivers and local environments. Lancet 2011;378:804-14

5. Patel CJ, Bhattacharya J, Butte AJ. An Environment-Wide Association Study (EWAS) on type 2 diabetes mellitus. PLOS ONE 2010;5:e10746.

6. Lanningham-Foster L, Nysse LJ, Levine JA. Labor saved, calories lost: the energetic impact of domestic labor-saving devices. Obes Res 2003;11:1178-81.

7. Chau JY, van der Ploeg HP, Merom D, et al. Cross-sectional associations between occupational and leisure-time sitting, physical activity and obesity in working adults. Prev Med 2012;54: 195-200.

8. Lakerveld J, Dunstan D, Bot S, et al. Abdominal obesity, TVviewing time and prospective declines in physical activity. Prev Med 2011;53:299-302.

9. Frank LD, Andresen MA, Schmid TL. Obesity relationships with community design, physical activity, and time spent in cars. Am J Prev Med 2004;27:87-96.
10. Dunstan DW, Salmon J, Healy GN, et al. Association of television viewing with fasting and 2-h postchallenge plasma glucose levels in adults without diagnosed diabetes. Diabetes Care 2007;30:516-22.

11. Ford ES, Schulze MB, Kroger J, et al. Television watching and incident diabetes: Findings from the European Prospective Investigation into Cancer and Nutrition-Potsdam Study. J Diabetes 2010;2:23-7.

12. Edwardson CL, Gorely T, Davies MJ, et al. Association of sedentary behaviour with metabolic syndrome: a meta-analysis. PLOS ONE 2012;7:e34916.

13. Meyer AM, Evenson KR, Couper DJ, et al. Television, physical activity, diet, and body weight status: the ARIC cohort. Int $J$ Behav Nutr Phys Act 2008;5:68.

14. Sisson SB, Broyles ST, Robledo C, et al. Television viewing and variations in energy intake in adults and children in the USA. Public Health Nutr 2012;15:609-17.

15. Banks E, Lim L, Seubsman SA, et al. Relationship of obesity to physical activity, domestic activities, and sedentary behaviours: cross-sectional findings from a national cohort of over 70000 Thai adults. BMC Public Health 2011;11:762.

16. Parra DC, Lobelo F, Gomez LF, et al. Household motor vehicle use and weight status among Colombian adults: Are we driving our way towards obesity? Prev Med 2009;49:179-83.

17. Teo K, Chow CK, Vaz M, et al. The Prospective Urban Rural Epidemiology (PURE) study: examining the impact of societal influences on chronic noncommunicable diseases in low-, middle-, and high-income countries. Am Heart J 2009;158:1-7 e1.

18. Yusuf S, Hawken S, Ounpuu S, et al. Effect of potentially modifiable risk factors associated with myocardial infarction in 52 countries (the INTERHEART study): case-control study. Lancet 2004;364:937-52.

19. Craig CL, Marshall AL, Sjostrom M, et al. International physical activity questionnaire: 12-country reliability and validity. Med Sci Sports Exerc 2003;35:1381-95.

20. Bharathi AV, Kurpad AV, Thomas T, et al. Development of food frequency questionnaires and a nutrient database for the Prospective Urban and Rural Epidemiological (PURE) pilot study in South India: methodological issues. Asia Pac J Clin Nutr 2008; $17: 178-85$

21. Dehghan M, Al Hamad N, Yusufali A, et al. Development of a semi-quantitative food frequency questionnaire for use in United Arab Emirates and Kuwait based on local foods. Nutr J 2005;4:18.

22. Dehghan M, Del Cerro S, Zhang X, et al. Validation of a semiquantitative food frequency questionnaire for argentinean adults. PLOS ONE 2012;7:e37958.

23. Dehghan M, Lopez Jaramillo P, Duenas R, et al. Development and validation of a quantitative food frequency questionnaire among rural- and urban-dwelling adults in Colombia. J Nutr Educ Behav 2012;44:609-13

24. Kelemen LE, Anand SS, Vuksan V, et al. Development and evaluation of cultural food frequency questionnaires for South Asians, Chinese, and Europeans in North America. J Am Diet Assoc 2003;103:1178-84

25. Merchant AT, Dehghan M, Chifamba J, et al. Nutrient estimation from an FFQ developed for a Black Zimbabwean population. Nutr J 2005;4:37.

26. Held C, Iqbal R, Lear SA, et al. Physical activity levels, ownership of goods promoting sedentary behaviour and risk of myocardial infarction: results of the INTERHEART study. Eur Heart $J$ 2012;33:452-66

27. Inoue $\mathrm{S}$, Sugiyama $\mathrm{T}$, Takamiya $\mathrm{T}$, et al. Television viewing time is associated with overweight/obesity among older adults, independent of meeting physical activity and health guidelines. $J$ Epidemiol 2012;22:50-6.

28. Zderic TW, Hamilton MT. Physical inactivity amplifies the sensitivity of skeletal muscle to the lipid-induced downregulation of lipoprotein lipase activity. J Appl Physiol 2006;100:249-57.

29. French SA, Mitchell NR, Hannan PJ. Decrease in television viewing predicts lower body mass index at 1-year follow-up in adolescents, but not adults. J Nutr Educ Behav 2012;44:415-22.

30. Dunstan DW, Kingwell BA, Larsen R, et al. Breaking up prolonged sitting reduces postprandial glucose and insulin responses. Diabetes Care 2012;35:976-83.

31. Healy GN, Dunstan DW, Salmon J, et al. Breaks in sedentary time: beneficial associations with metabolic risk. Diabetes Care 2008 31:661-6.

32. Bennie JA, Timperio AF, Crawford DA, et al. Associations between social ecological factors and self-reported short physical activity breaks during work hours among desk-based employees. Prev Med 2011;53:44-7.

33. Gilson ND, Puig-Ribera A, McKenna J, et al. Do walking strategies to increase physical activity reduce reported sitting in workplaces: a randomized control trial. Int J Behav Nutr Phys Act 2009; $6: 43$. 
Affiliations: Faculty of Health Sciences, Simon Fraser University and Division of Cardiology, Providence Health Care (Lear), Vancouver, BC; Population Health Research Institute (Teo, Zhang, Rangarajan, Anand, Yusuf), Hamilton Health Sciences, McMaster University, Hamilton, Ont.; Department of Biomedical Physiology and Kinesiology (Gasevic), Simon Fraser University Burnaby, BC; Institut universitaire de cardiologie et de pneumologie de Québec (Poirier), Québec City, Que.; Department of Internal Medicine (Seron), Universidad de La Frontera, Temuco, Chile; Isfahan Cardiovascular Research Institute, and Child Growth and Development Research Center (Kelishadi), Isfahan University of Medical Sciences, Isfahan, Iran; Universiti Kebangsaan Malaysia (Tamil), Kuala Lumpur, Malaysia; Afrika-Eenheid vir Transdissiplinêre Gesondheidsnavorsing, Fakulteit Gesondheidswetenskappe (Kruger), Noordwes-Universiteit, Potchefstroom, South Africa; Department of Community Health Sciences and Medicine (Iqbal), Aga Khan University, Karachi, Pakistan; Dubai Medical College and Primary Health Care Sector (Swidan), Dubai Health Authority, Dubai, United Arab Emirates; Departamento de Investigación, Fundación Oftalmológica de Santander (Gómez-Arbeláez), Facultad de Medicina, Universidad de Santander, Bucaramanga, Santander, Colombia; School of Life Sciences and Centre for Health (Yusuf), Population and Development, Independent University, Bangladesh, Dhaka, Bangladesh; Department of Physiology (Chifamba), University of Zimbabwe College of Health Sciences, Harare, Zimbabwe; Sree Chitra Tirunal Institute for Medical Sciences and Technology (Kutty), Trivandrum, India; Division of Endocrinology and Metabolism (Karsidag), Department of Internal Medicine, Istanbul Faculty of Medicine, Istanbul University, Istanbul, Turkey; School of Public Health (Kumar), Post-Graduate Institute of Medical Education and Research, Chandigarh, India; Medical Research and Biometrics Center (Li), National Center for Cardiovascular Diseases, Cardiovascular Institute and Fuwai Hospital, Chinese Academy of Medical Sciences, Beijing, China; Department of Internal Medicine (Szuba), Wroclaw Medical University, Wroclaw, Poland; Dante Pazzanese Institute of Cardiology (Avezum), Sao Paulo, Brazil; Estudios Clinicos Latinoamerica ECLA (Diaz), Rosario, Santa Fe, Argentina; Department of Molecular and Clinical Medicine (Rosengren), Sahlgrenska Academy, University of Gothenburg, Gothenburg, Sweden

Contributors: Scott Lear had full access to all of the data in the study and takes responsibility for the integrity of the data and the accuracy of the data analysis. Scott Lear and Salim Yusuf conceived the analyses and developed the study concepts. Scott Lear supervised the data analysis and had primary responsibility for writing the manuscript. Salim Yusuf was the principal investigator of the PURE study, supervised its conduct and reviewed and commented on drafts of the manuscript. Sumathy Rangarajan coordinated the worldwide study, reviewed and commented on drafts of the manuscript. Xiaohe Zhang performed all data analyses, reviewed and commented on drafts. All other authors coordinated the study in their respective countries, provided critical revisions and approved the final version of the manuscript submitted.

Funding: The main PURE study and its components are funded by the Population Health Research Institute, the Canadian Institutes of Health Research, Heart and Stroke Foundation of Ontario and through unrestricted grants from several pharmaceutical companies (with major contributions from Astra Zeneca [Canada], Sanofi-Aventis [France, Canada], Boehringer Ingelheim [Germany, Canada], Servier, GlaxoSmithKline); additional contributions were made by Novartis, King Pharma and by various national or local organizations in the participating countries. These include the following countries: Bangladesh: Independent University, Bangladesh, Mitra and Associates; Brazil: Unilever Health Institute, Brazil; Canada: Public Health Agency of Canada and Champlain Cardiovascular Disease Prevention Network; Chile: Universidad de la Frontera; China: National Center for Cardiovascular Diseases; Colombia: Colciencias, Grant number: 6566-04-18062; India: Indian Council of Medical Research; Malaysia: Ministry of Science, Technology and Innovation of Malaysia (grant no. 100-IRDC/BIOTEK 16/6/21 [13/2007], 07-05-IFN-MEB010), Ministry of Higher Education of Malaysia (grant no. 600-RMI/LRGS/5/3 [2/2011]), Universiti Teknologi MARA, Universiti Kebangsaan Malaysia (UKM-Hejim-Komuniti-15-2010); Poland: Polish Ministry of Science and Higher Education (grant no. 290/W-PURE/2008/0), Wroclaw Medical University; South Africa: The North-West University, South Africa and Netherlands Programme for Alternative Development, National Research Foundation, Medical Research Council of South Africa, The South Africa Sugar Association, Faculty of Community and Health Sciences; Sweden: AFA Insurance, Swedish Council for Working Life and Social Research, Swedish Research Council for Environment, Agricultural Sciences and Spatial Planning, Swedish Heart and Lung Foundation, Swedish Research Council, Grant from the Swedish State under (Läkar Utbildnings Avtalet), Agreement, Grant from the Västra Götaland Region (FOUU); Turkey: Metabolic Syndrome Society, Astra Zeneca, Turkey, Sanofi Aventis, Turkey; United Arab Emirates: Sheikh Hamdan Bin Rashid Al Maktoum Award For Medical Sciences, Dubai Health Authority, Dubai, United Arab Emirates.

Acknowledgements: Scott Lear holds the Pfizer/Heart and Stroke Foundation Chair in Cardiovascular Prevention Research at St. Paul's Hospital. Salim Yusuf is the Heart and Stroke Foundation of Ontario/Marion W. Burke Chair in Cardiovascular Disease. Paul Poirier is a senior clinical-research scholar from the Fonds de la recherche en santé du Québec. 